Check for updates

Cite this: RSC Adv., 2019, 9, 14649

\title{
Thin layer broadband porous chromium black absorber fabricated through wet-etching process
}

\author{
Lang Zhou, (D) ab Zhuo Li, ${ }^{\text {ab }}$ Jinying Zhang, ${ }^{\text {ab }}$ Defang Li, ${ }^{\text {ab }}$ Dan Liu, ${ }^{\text {ab }}$ Yajie Li ${ }^{\text {ab }}$ \\ and Xin Wang*ab
}

A thin layer porous chromium (Cr) black absorber was fabricated on a polyimide (PI) substrate with 2 inch diameter and $500 \mathrm{~nm}$ thickness. The chromium black was prepared by electron beam evaporation and wet-etching process. To optimize the parameters of the absorber, the $\mathrm{Cr}$ black was firstly fabricated on silicon and quartz wafers. A high average absorption of $93 \%$ over the whole visible spectrum (320 nm to $800 \mathrm{~nm}$ ) was obtained by 3 min wet-etching of a $400 \mathrm{~nm}$ thick metal $\mathrm{Cr}$ film. The absorption was higher than 65\% when the spectrum extended to near infrared from 800 to $1800 \mathrm{~nm}$. The mechanism of the ultra-broadband absorption can be explained by the light trapping by numerous nanovoids formed inside the $\mathrm{Cr}$ film. The nanovoid acts as a blackbody cavity, where the incident light experienced multiple reflections. Using the optimized parameters obtained with silicon and quartz wafers, the $\mathrm{Cr}$ black absorber was fabricated on a PI film. Due to its porous structure (low density) and thin thickness, the $\mathrm{Cr}$ black/PI composite film showed a strong light absorption and a high optical thermal response. Compared to a PI film without $\mathrm{Cr}$ black layer, the average absorption of the composite film was increased from $5.0 \%$ to $93.4 \%$, the optical thermal response was improved by 43.5 times. This property highlights its potential applications in various fields such as photo detection and thermal imaging.

Received 22nd January 2019 Accepted 30th April 2019

DOI: $10.1039 / c 9 r a 00559 e$

rsc.li/rsc-advances designed from microwave to visible. ${ }^{14-16}$ But the absorption bandwidth is usually narrow due to their intrinsic wave resonance. To extend the absorption spectral bandwidth, multiorder mode ${ }^{17,18}$ or multiple resonators ${ }^{19-22}$ had to be designed. The sophisticated nanofabrication procedures hindered their mass production for practical applications, especially when the desired absorption wavelength is in the visible spectrum. ${ }^{19}$ To achieve broadband and angle insensitive absorption, nickelphosphorus absorber with $5 \mu \mathrm{m}$-depth etched pores $^{23,24}$ and vertically aligned carbon nanotube arrays with the thicknesses varied in the range of $10-800 \mu \mathrm{m}{ }^{25-27}$ were fabricated. The high broadband absorption is brought by the multiple reflection inside the nanostructures. Among different nanostructures, nanocone with rough surface is proved to be the most efficient. Various absorbers based on nanocones, such as black silicon $^{28-30}$ and metallic nanocone arrays ${ }^{31-33}$ were fabricated. Their broadband absorption is higher than $99 \%$. But these kind of thick (tens of micrometers) and heavy absorbers are not suitable to be used on soft polymer films. Otherwise, the flexibility and thermal properties of thin PI films would be totally changed. Loosely porous gold black ${ }^{34}$ and aluminium black ${ }^{35}$ not only have broadband absorption but also can be fabricated on thin polymer films. However, the adhesion on the substrates is not strong due to both the metal crystal structures and the heat evaporation coating technology. In addition, because of their mechanical fragility ${ }^{36}$ the gold or aluminium black 
coatings are easily broken when there is a force or a temperature change.

In this paper, a thin porous Cr black absorber with no more than $400 \mathrm{~nm}$ thickness is fabricated on a $500 \mathrm{~nm}$ thick free-standing PI film. Compared to gold and aluminium, $\mathrm{Cr}$ film shows better adhesion to silicon, oxide glass and polymer substrates. ${ }^{37,38} \mathrm{~A}$ dense metal $\mathrm{Cr}$ film was deposited by electro-beam evaporation on substrate, which ensured good adhesion, uniformity and mechanical strength. Micro- and nano-voids were formed on the $\mathrm{Cr}$ thin film via wet-etching with Cr corrosive solution. The size of the micro- and nanovoids and the absorption could be controlled by wetetching parameters.

To get the optimized fabrication parameters, a number of $\mathrm{Cr}$ black absorber samples were fabricated on Si and quartz wafers. The samples made on Si substrate were used for crystal structure, film morphology, optical reflection from ultraviolet-visible (UV-VIS) to near infrared (NIR) range and NIR range transmission measurements. The samples made on quartz substrate were used for UV-VIS range transmission measurement. With 3 min wet-etching of a $400 \mathrm{~nm}$ thick metal Cr film, the Cr black absorber showed an average absorption as high as $93 \%$ covering a wide spectrum from $320 \mathrm{~nm}$ to $800 \mathrm{~nm}$. Finally, by using the optimized parameter we obtained from Si and quartz wafers, the high absorption Cr black absorber was fabricated on a 500 nm-thick PI film with 2 inch diameter. Compared to a bare PI film, the average absorption was increased from 5\% to $93.4 \%$, the optical thermal response of the Cr black/PI composite film had a 43.5 times enhancement. In addition, compared to absorbers based on periodic electric ring resonators and nanocones, the deposition/wet-etching process is easier to accomplish, more efficient and low-cost, which makes mass production possible.

\section{Experimental section}

\subsection{Material}

One side polished Si (100) and quartz wafers (500 $\mu \mathrm{m}$ thickness, 2 inch diameter, Tianjin semiconductor research institute) were used as substrates for Cr black absorber sample fabrication. $\mathrm{Cr}$ particles (99.95\% purity, 3 to $5 \mathrm{~mm}$ diameter, ZNXC technology co., LTD, China) were used for metal $\mathrm{Cr}$ film preparation. Ammonium ceric nitrate $\left(\mathrm{NH}_{4}\right)_{2} \mathrm{Ce}\left(\mathrm{NO}_{3}\right)_{6}$ powder $(99.0 \%$, Macklin), glacial acetic acid (36\%, Macklin) and distilled water were used to produce corrosive solution for $\mathrm{Cr}$ wet-etching.

$\mathrm{SiO}_{2}(300 \mathrm{~nm}) / \mathrm{Si}(500 \mu \mathrm{m})$ wafer (2 inch diameter, Tianjin semiconductor research institute) was used as substrates for free-standing $\mathrm{Cr}$ black/PI composite film fabrication. Liquid poly(amic acid) (PAA) solution with the viscosity of 300-400 cps $\left(25^{\circ} \mathrm{C}\right.$ ) and the solid content of $12-13 \%$ (ZKPI-305IIB, POME technology) was used as the PI precursor. Hydrofluoride acid (40\%, Macklin) was used to wet-etch $\mathrm{SiO}_{2}$ sacrificial layer.

\subsection{Preparation of $\mathrm{Cr}$ black absorber samples}

$\mathrm{Cr}$ absorbers samples were prepared on $\mathrm{Si}$ (100) or quartz wafers. The wafers were soaked in a $100{ }^{\circ} \mathrm{C}$ piranha solution $(3$ parts $\mathrm{H}_{2} \mathrm{SO}_{4}$ to 1 part $30 \mathrm{wt} \% \mathrm{H}_{2} \mathrm{O}_{2}$ by volume) for $15 \mathrm{~min}$ and then thoroughly rinsed with distilled water for wet-chemical cleaning. After that, high purity $\mathrm{Cr}$ particles with the diameter of 3 to $5 \mathrm{~mm}$ were used to deposit metal $\mathrm{Cr}$ film on the cleaned wafers by electron-beam evaporating at $5 \times 10^{-6}$ Torr (NEXDEP, Angstrom Engineering). The wafer temperature was $110^{\circ} \mathrm{C}$ and the evaporation rate was $0.1 \mathrm{~nm} \mathrm{~s}^{-1}$. The thickness of Cr films was monitored in situ by a quartz crystal oscillator and further calibrated by step profiler. A Cr metal film with $400 \mathrm{~nm}$ thickness was deposited on wafers.

The wafers with $\mathrm{Cr}$ metal film were cut into $2 \mathrm{~cm} \times 4 \mathrm{~cm}$ small samples, then dipped into $\mathrm{Cr}$ corrosive solution for wetetching. Cr corrosive solution was prepared by $25 \mathrm{~g}\left(\mathrm{NH}_{4}\right)_{2}$ $\mathrm{Ce}\left(\mathrm{NO}_{3}\right)_{6}$ powder, $20 \mathrm{ml}$ glacial acetic acid and $100 \mathrm{ml}$ distilled water. The solution temperature was kept at $20^{\circ} \mathrm{C}$. The metal $\mathrm{Cr}$ films was wet-etched through the following chemistry reaction:

$$
\begin{aligned}
\left(\mathrm{NH}_{4}\right)_{2} \mathrm{Ce}\left(\mathrm{NO}_{3}\right)_{6}+\mathrm{Cr} \rightarrow & \mathrm{Cr}\left(\mathrm{NO}_{3}\right)_{2}+\mathrm{Ce}\left(\mathrm{NO}_{3}\right)_{2} \\
& +2 \mathrm{NH}_{4} \mathrm{NO}_{3}+\mathrm{H}_{2} \mathrm{O}
\end{aligned}
$$

where the reaction products were completely dissolved in the solution, so that the nanovoids on the surface of Cr film was formed. The etching time was varied from 0 to $4 \mathrm{~min}$ for different samples to get different absorber structure and morphology. The overall procedure to prepare the $\mathrm{Cr}$ black absorbers on Si or quartz substrates was presented schematically in Fig. 1.

\subsection{Preparation of the free-standing $\mathrm{Cr}$ black/PI composite film}

The Cr black/PI free-standing film fabrication began with the wet-chemical cleaning of 2 inch $\mathrm{SiO}_{2}(300 \mathrm{~nm}) / \mathrm{Si}(500 \mu \mathrm{m})$ thermal oxide wafers. PAA solution was used as the PI precursor. To enhance the adhesion between PAA layer and $\mathrm{SiO}_{2}$, the wafer was surface modified in $\mathrm{Ar}-\mathrm{O}_{2}$ atmosphere for $2 \mathrm{~min}$. The radio-frequency (RF) power was $100 \mathrm{~W}$ (GIGAbatch $310 \mathrm{M}$, PVA TePla AG). The gas flows of Ar and $\mathrm{O}_{2}$ were $20 \mathrm{sccm}$ and $100 \mathrm{sccm}$, respectively. $6 \mathrm{ml}$ PAA solution was spin-coated on the $\mathrm{SiO}_{2}$ layer at the low speed of $800 \mathrm{rpm}$ for $1 \mathrm{~min}$, then followed by the high speed of $4000 \mathrm{rpm}$ for $3 \mathrm{~min}$ (LabSpin6, SUSS MicroTec). The PAA coating was then air-dried at room temperature for $1 \mathrm{~h}$, and cured in a high temperature oven filled with nitrogen gas with temperatures increasing steps at 100 , 200, 250 and $300{ }^{\circ} \mathrm{C} \mathrm{(1} \mathrm{h} \mathrm{at} \mathrm{each} \mathrm{temperature).} \mathrm{After} \mathrm{that,} \mathrm{the}$ PAA coating was cooled naturally from $300{ }^{\circ} \mathrm{C}$ to room temperature. The formation of PI was verified by its particular canary yellow color, as a thin transparent film. The thickness of

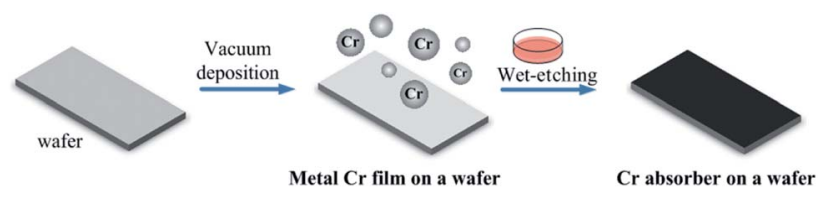

Fig. 1 The overall procedure to prepare $\mathrm{Cr}$ black absorbers on Si or quartz substrates. 
the PI film was measured by a surfagauge (Surftest SJ-140, Mitutoyo). Using the above process parameters, a PI film with the thickness of $500 \mathrm{~nm}$ was made. To overlay a $\mathrm{Cr}$ black absorber on PI film, a $400 \mathrm{~nm}$ metal $\mathrm{Cr}$ film was vacuum deposited on PI film first, then the film was wet-etched for $3 \mathrm{~min}$ to form the optimized porous Cr black structure. Prior to delamination process, the stress of the Cr black/PI composite film was dispersed on a $500{ }^{\circ} \mathrm{C}$ hot plate for $1 \mathrm{~h}$. To make the $\mathrm{Cr}$ black/PI composite film free-standing, the $\mathrm{SiO}_{2}$ sacrificial layer was removed completely by wet-etching in hydrofluoride acid solution for $10 \mathrm{~min}$. So that, the 2 inch black/PI composite film peeled off from the Si substrate totally and floated over the surface of solution. In the end, the composite film was transferred gently and supported by a PI ring. The overall procedure to prepare the free-standing Cr black/PI composite film was presented schematically in Fig. 2.

\subsection{Characterization methods}

X-ray diffraction (XRD) patterns of the metal $\mathrm{Cr}$ film and $\mathrm{Cr}$ black absorber samples on Si substrate were acquired using $\mathrm{Cu}-\mathrm{K} \alpha$ radiation $(\lambda=0.15418 \mathrm{~nm})$, at an accelerating voltage of $40 \mathrm{kV}$ and current of $40 \mathrm{~mA}$ (Rigaku Ultima IV). The detailed surface morphologies of the metal $\mathrm{Cr}$ film and $\mathrm{Cr}$ black absorber samples on Si substrate were characterized by field emission scanning electron microscopy (FE-SEM, Zeiss SUPRA $^{\mathrm{TM}} 55$ SAPPHIRE) and atomic force microscopy (AFM, Multimode8, BRUKER). Integrated reflectance and transmittance spectra of Cr absorbers in the range of 320-1800 nm were obtained by a PerkinElmer Lambda 19 spectrometer with an integration sphere. The light incident angle was $0^{\circ}$. The light sources were a tungsten halogen and a deuterium lamp, the detectors were photomultiplier and lead sulfide detector for UV-VIS and NIR, respectively. In reflectance measurement, the sample substrate was Si. In transmittance measurement, the sample substrates were quartz in UV/VIS region and $\mathrm{Si}$ in NIR region, respectively, to obtain good light transparency. For the reflectance measurement the results were normalized to a Labsphere Spectralon reflectance standard.

To deduce the absorption of the Cr black absorber the transmittances of both the samples and the substrates were measured. According to the sample transmittance expression ${ }^{25}$

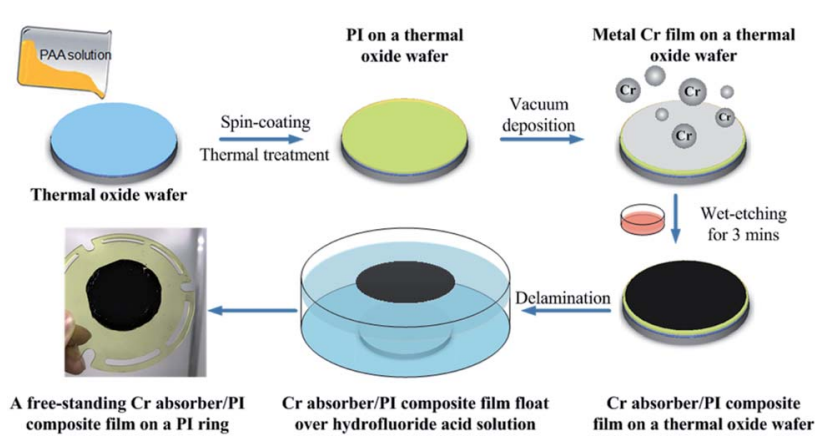

Fig. 2 The overall procedure to prepare the free-standing $\mathrm{Cr}$ black/PI composite film.

$$
T_{\text {sample }} \approx T_{\mathrm{Cr}} \times T_{\text {substrate }}
$$

where $T_{\text {sample }}, T_{\mathrm{Cr}}$ and $T_{\text {substrate }}$ are the transmittances of measured samples (Cr black absorber on substrate, Cr black absorbers and substrates, respectively); the transmittance of $\mathrm{Cr}$ black absorbers can be calculated.

Assuming the light reflected by the substrate to the $\mathrm{Cr}$ black absorber is either absorbed or passed through the $\mathrm{Cr}$ black absorber; as illustrated in Fig. 3. Due to the low transmittance of $\mathrm{Cr}$ film, the light energy reflected by substrate was as low as $\sim 4 \%$, which was negligible. Thus, $R_{\text {sample }}$ (reflectance of the samples) was determined mainly by $R_{\mathrm{Cr}}$ (reflectance of the black absorbers). The integrated absorption of the Cr black absorber $\left(A_{\mathrm{Cr}}\right)$ could be calculated by the following relations between absorption, reflection and transmission:

$$
\begin{gathered}
A_{\text {sample }} \approx 1-R_{\mathrm{Cr}}-T_{\text {sample }} \\
A_{\mathrm{Cr}} \approx 1-R_{\mathrm{Cr}}-T_{\mathrm{Cr}}
\end{gathered}
$$

where $R_{\mathrm{Cr}}\left(\approx R_{\text {sample }}\right)$ is the measured reflectance of the samples, $A_{\text {sample }}$ is the calculated absorption of samples.

The optical thermal responses and thermal decay time of a $\mathrm{Cr}$ black/PI composite film were investigated. The measurement schematic is shown in Fig. 4. An intensity modulated solid-state laser operating at $532 \mathrm{~nm}$ wavelength was used as an exciting light source. The modulation frequency was $5 \mathrm{~Hz}$ and duty cycle was $50 \%$. The laser peak power was $1.2 \mathrm{~W}$. The diameter of the laser beam was 20 $\mathrm{mm}$. The film was placed in a vacuum chamber with pressure of $1 \times 10^{-6}$ Torr to decrease the heat convection. The vacuum chamber has two optical windows. One is a fused quartz window with antireflection coating from $350 \mathrm{~nm}$ to $800 \mathrm{~nm}$ spectrum for visible light transmission, the other is a germanium window with antireflection coating from $3 \mu \mathrm{m}$ to $5 \mu \mathrm{m}$ spectrum for middle wave infrared (MWIR) transmission. The laser beam incident normally to the surface of the sample through the fused quartz window. By absorbing the light, the temperature of the Cr black/PI composite film
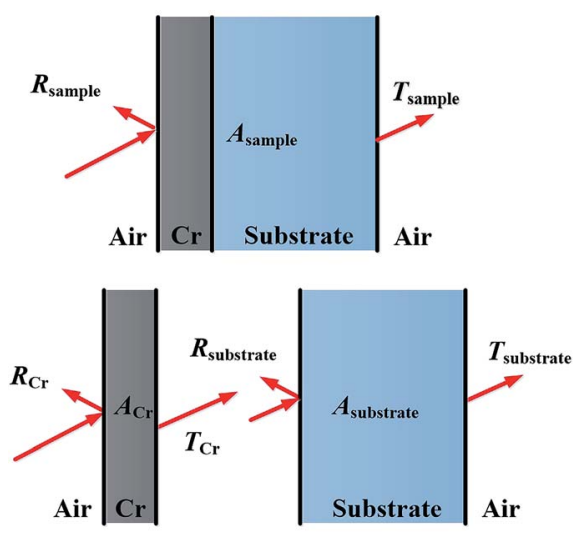

Fig. 3 Illustration of the absorption calculations of the $\mathrm{Cr}$ black absorbers. 


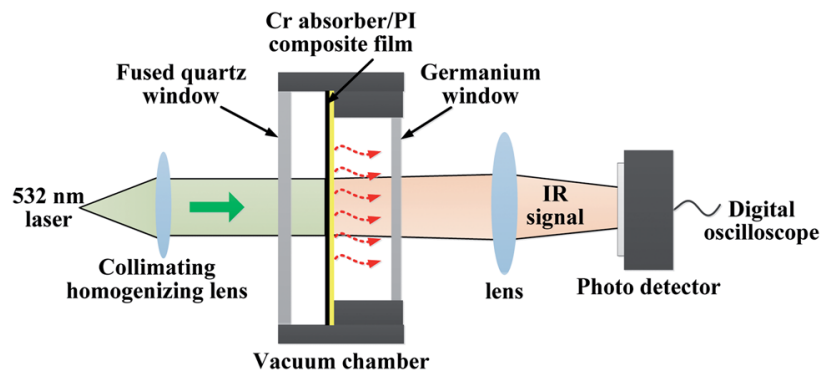

Fig. 4 The measurement schematic of optical thermal responses and thermal decay time.

changed according to the laser intensity modulation. Thus, a modulated thermal radiation was observed. The radiation was collected by optics and directed to a MWIR photo detector (PD) through the germanium window. The output signal of the PD is sampled by a digital oscilloscope for further analysis.

\section{Results and discussion}

\subsection{Morphology}

Fig. 5 shows the crystal quality of a $400 \mathrm{~nm}$ metal $\mathrm{Cr}$ film and 3 min wet-etching $\mathrm{Cr}$ black absorber sample. The strong peak of Si (substrate) was not shown in this figure. The strong and sharp peak near $2 \theta=44.4^{\circ}$ corresponds to the $\mathrm{Cr}$ (110) crystal orientation, shown in Fig. 2(a). The full width at half maximum (FWHM) of the curve is $0.6^{\circ}$. Based on the Bragg diffraction angle and the FWHM of the diffraction pattern in the $2 \theta$ scan, the average grain size of the metal $\mathrm{Cr}$ film is estimated to be $13 \mathrm{~nm}$ by Debye-Scherrer formula. Meanwhile, the diffraction peaks at $2 \theta=64.6^{\circ}(200)$ and $81.7^{\circ}(211)$ are hardly to be observed due to the thin thickness of $\mathrm{Cr}$ film. During wet-etching process, $\mathrm{Cr}$ atoms gradually reacted with $\left(\mathrm{NH}_{4}\right)_{2} \mathrm{Ce}\left(\mathrm{NO}_{3}\right)_{6}$ in acid environment. The products, $\mathrm{Cr}\left(\mathrm{NO}_{3}\right)_{2}$

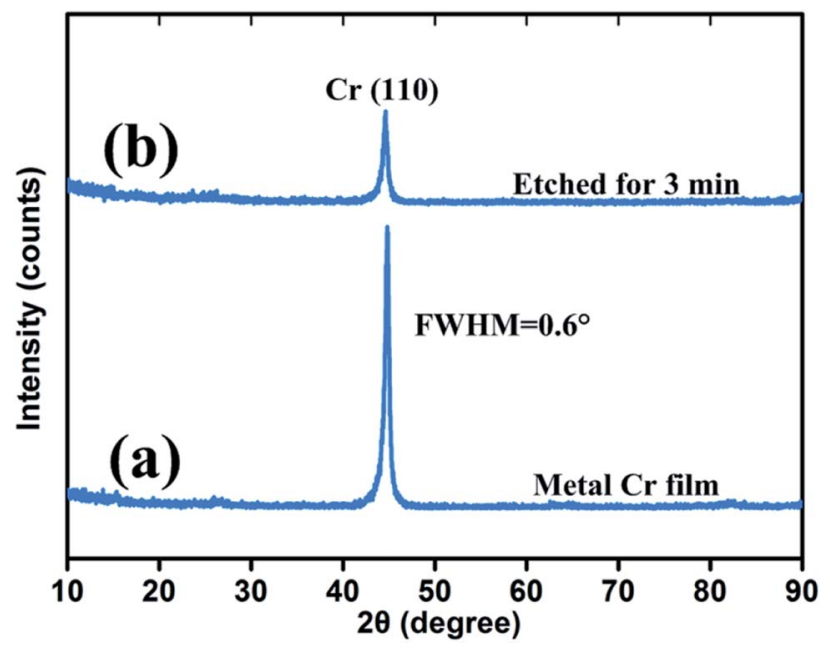

Fig. 5 XRD measurement results of metal $\mathrm{Cr}$ film and $\mathrm{Cr}$ black absorber on Si substrates. and $\mathrm{Ce}\left(\mathrm{NO}_{3}\right)_{2}$ were completely dissolved in solution. Thus, a porous $\mathrm{Cr}$ film was formed by randomly spatial atom lost. The forming process was improved by the 3 min wet-etching sample scan, shown in Fig. 2(b), where the intensity of the $\mathrm{Cr}$ (110) peak decreased and the FWHM of the curve became broaden. In addition, no new peak is observed. The result indicates that there is no new byproduct contained by porous Cr black absorbers from the wet-etching chemical reaction. The observed grey and black appearance were due to the light-trapping of porous $\mathrm{Cr}$ nanostructures, as shown in SEM images of Fig. 6.

Fig. 6 shows the surface morphologies of metal $\mathrm{Cr}$ film and Cr black absorber samples with different wet-etching times. Surface details were further investigated by AFM, as shown in Fig. 7. For $400 \mathrm{~nm}$ metal $\mathrm{Cr}$ film without wet-etching, the root mean square (RMS) of the surface roughness is $3.9 \mathrm{~nm}$ within a $5 \mu \mathrm{m} \times 5 \mu \mathrm{m}$ area; the surface fluctuation from peak to valley is $17 \mathrm{~nm}$; as shown in Fig. 7(a)-(c). It indicates that the surface of the metal $\mathrm{Cr}$ film is smooth and shows specular reflection. After 2 min etching (Fig. 6(b)), innumerable voids (black region) appeared. The Cr cluster diameter is tens of nanometers. These voids form innumerable black body cavities, to capture and absorb the incident light. As the etching time increasing, the black voids became deeper and bigger. After 3 min wet-etching, voids were connected to each other, resulting in the formation of voids with the big average diameter of $200 \mathrm{~nm}$, as shown in Fig. 6(c). Observed by AFM, the RMS of the Cr layer surface increases to $50.5 \mathrm{~nm}$ and the largest surface fluctuation from peak to valley is up to $240 \mathrm{~nm}$, as shown in Fig. 7(f). After 4 min, the voids were destroyed and parts of $\mathrm{Si}$ substrate were exposed, as in Fig. 6(d). After 7-8 min, the metal $\mathrm{Cr}$ film was corroded completely.

\subsection{Optical properties}

To investigate the light absorption properties of $\mathrm{Cr}$ black absorbers, the transmission and reflection of the Cr black
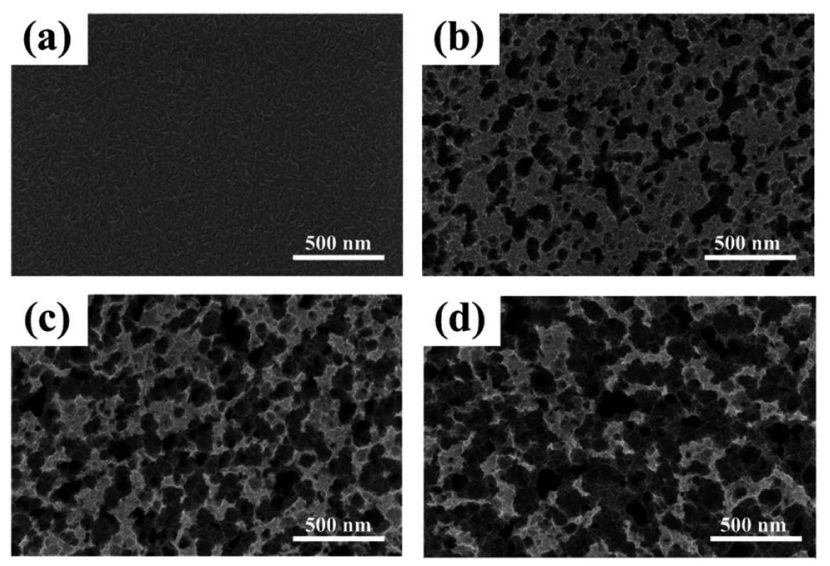

Fig. 6 FE-SEM images of metal $\mathrm{Cr}$ film and $\mathrm{Cr}$ black absorbers on $\mathrm{Si}$ substrate with different wet-etching times. (a) Metal Cr film, (b) etched for $2 \mathrm{~min}$, (c) etched for $3 \mathrm{~min}$, (d) etched for $4 \mathrm{~min}$. 
(a)

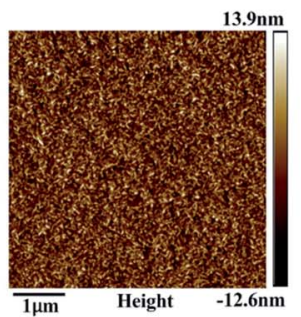

(c)



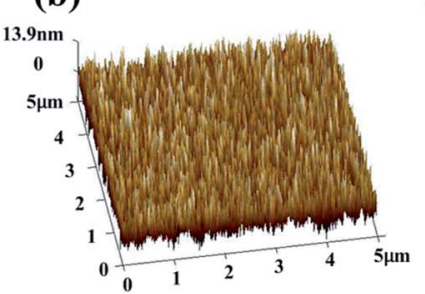

(d)

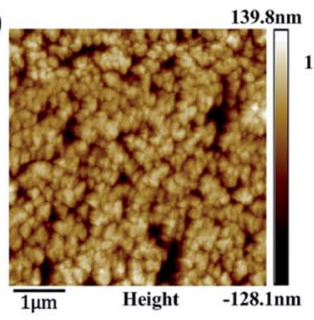

(e)

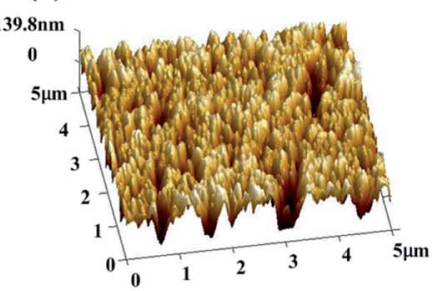

(f)

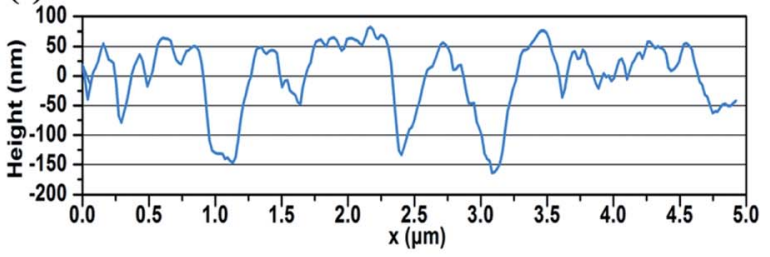

Fig. 7 (a) The top-view AFM image, (b) three-dimensional AFM image and (c) surface fluctuation profile of $400 \mathrm{~nm}$ metal Cr film on Si substrate; (d) the top-view AFM image, (e) three-dimensional AFM image and (f) surface fluctuation profile of Cr black absorber on Si substrate etched for 3 min.

absorber samples were measured. For transmission measurements, the substrate has to be transparent in certain spectral range. Therefore, the $\mathrm{Cr}$ black absorber samples fabricated on quartz were used in the transmission measurements in UV-VIS region (from $320 \mathrm{~nm}$ to $1100 \mathrm{~nm}$ ). In the spectral range of $1100 \mathrm{~nm}$ to $1800 \mathrm{~nm}$, Si substrate was used instead. Fig. 8 is the photo of the $\mathrm{Cr}$ black absorber samples with $0,2,3,4$ min wet-etching, respectively. The metal Cr layer has a silvery metallic appearance. In comparison, the Cr black film fabricated with 3 min wet-etching time has a matted black, glossy appearance. Fig. 8 shows the reflectance and colour changes at different wet-etching times.

The transmission spectra of 3 min etched Cr black absorber samples on $\mathrm{Si}$ and quartz were shown in Fig. 9(a) by black squares and red dots, respectively. With the known transmittances of the substrates, the transmission spectrum of $\mathrm{Cr}$ black absorber from $320 \mathrm{~nm}$ to $1800 \mathrm{~nm}$ was calculated by formula (2).

Fig. 9(b) is the reflectance measurement results of the $\mathrm{Cr}$ black absorber samples on Si substrate, with different wetetching times. It indicates that the rougher the absorber surface is, the lower reflectance it has.
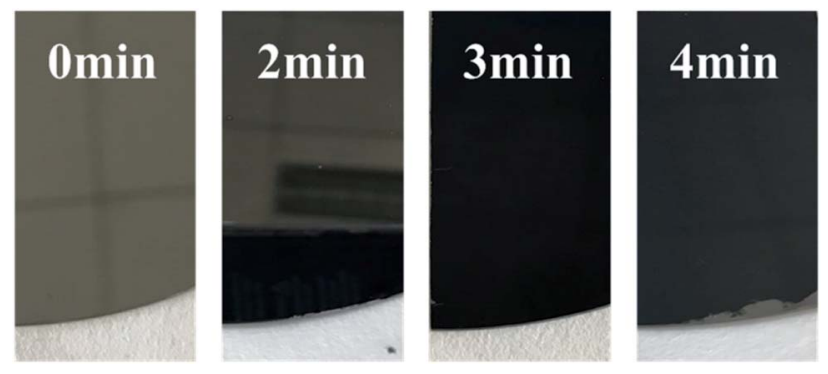

Fig. 8 Photographs of metal $\mathrm{Cr}$ films and $\mathrm{Cr}$ black absorbers with different wet-etching time on Si (100) substrate.
With the results shown in Fig. 9(a) and (b), the integrated absorption $\left(A_{\mathrm{Cr}}\right)$ spectra of Cr black absorbers were calculated by formula (3-2). The calculation results are shown in Fig. 9(c). The dithering at $860 \mathrm{~nm}$ is due to grating switching of the spectrometer. The average absorption of metal Cr film is about $46 \%$ in the range of $600 \mathrm{~nm}$ to $1300 \mathrm{~nm}$ and decreases in the UV and NIR regions. This absorption can be correlated with the free electron oscillation of $\mathrm{Cr}$ atoms with the incident light. After 2 min etching, the average absorption dramatically increases to $80 \%$ in visible range, indicating the formation of porous nanostructures. When the etching time is up to $3 \mathrm{~min}$, the average absorption exceeds $93 \%$ from $320 \mathrm{~nm}$ to $800 \mathrm{~nm}$, and the highest absorption is up to $95 \%$ at $530 \mathrm{~nm}$. To extend to the NIR region, the absorption decreases linearly from $93 \%$ to $65 \%$ with a slope of $-0.02 \% \mathrm{~nm}^{-1}$. These phenomenon could be correlated with the large imaginary part of Cr permittivity. ${ }^{39}$ The incident light energy dissipates rapidly along the large rough $\mathrm{Cr}$ surface within a short propagation distance, resulting in a high optical absorption. In addition, $\mathrm{Cr}$ nanovoids with gradual diameter variations in a wide range make the impedance match well with free space in a broad wavelength range, which significantly reduces the surface reflection and enhances absorption. ${ }^{31}$ The decreased absorption at 4 min etching time is due to the reduction of film thickness and voids destruction, as shown in Fig. 6(d).

Since Spectralon delivers a constant reflectance of $99 \%$ from $300 \mathrm{~nm}$ to about $1600 \mathrm{~nm}$, and even lower reflectance at higher wavelengths $(1750-2500 \mathrm{~nm}){ }^{\mathbf{4 0 , 4 1}}$ the systematic error of the reflectance measurements is considered to be $1 \%$. In addition, the impurities and scratches of the optical components will reduce the Spectralon's reflectance, leading to an underestimation of the sample absorption by at least $2 \%$ of the measured value.

Using the corrected absorption of the Cr black absorber with 3 min wet-etching, the average absorption coefficients $\alpha_{\lambda}$ is calculated by

$$
A_{\mathrm{Cr}}=1-\exp \left(-\alpha_{\lambda} d\right)
$$


(a)

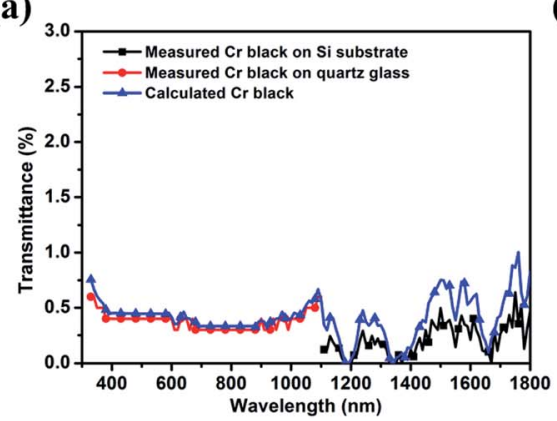

(b)

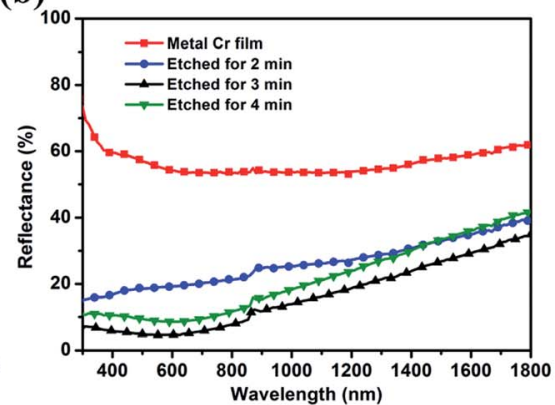

(c)

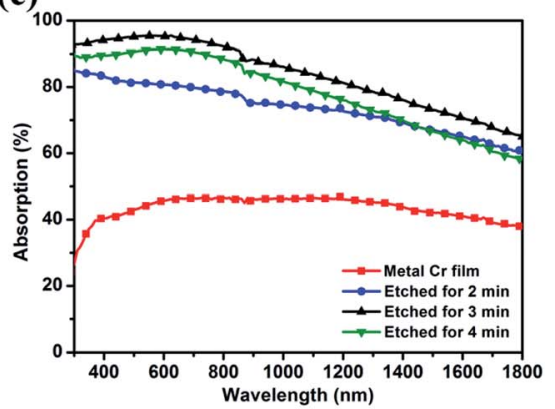

Fig. 9 (a) Transmission spectra of the $\mathrm{Cr}$ black absorber samples on quartz glass and Si substrate for 3 min wet-etching and the calculated transmission spectrum of the $\mathrm{Cr}$ black absorber. (b) Reflectance spectra of metal $\mathrm{Cr}$ film and $\mathrm{Cr}$ black absorbers on $\mathrm{Si}$ substrates with different wet-etching times. (c) Calculated absorption spectra of metal $\mathrm{Cr}$ film and $\mathrm{Cr}$ black absorbers with different wet-etching times.

where $d$ is the absorbers thickness. In the visible range, the average absorption coefficient of Cr black absorber was 6.6 $\mu \mathrm{m}^{-1}$, which is higher than $1.1 \mu \mathrm{m}^{-1}$ of black nickel-phosphorus $^{23}$ and $0.7 \mu \mathrm{m}^{-1}$ of vertically aligned carbon nanotube arrays. ${ }^{26}$

\subsection{Optical thermal response}

In this section, the optical-thermal response of the freestanding Cr black/PI composite film with a diameter of 2 inch is investigated. The $\mathrm{Cr}$ black absorber was made by $3 \mathrm{~min}$ wet-etching of a $400 \mathrm{~nm}$ thick metal $\mathrm{Cr}$ film and the thickness of the PI was $500 \mathrm{~nm}$. Ref. 42 gives an average absorption of $5 \%$ for pure PI thin film in UV-VIS. ${ }^{42}$ Using the result in Fig. 9(c), the absorption of the Cr black/PI composite film would be 93.4\%. Fig. 10(a) shows the normalized thermal radiation intensities of $\mathrm{Cr}$ black/PI composite film and bare PI film under the same incident light excitation. The $\mathrm{Cr}$ black/PI composite film shows a much higher optical thermal responsibility, while the bare PI film had very weak thermal radiation due to low absorption at $532 \mathrm{~nm}$. By thermal radiation intensity normalization, the maximum radiation intensities of the Cr black/PI composite film and the bare PI film are 1 and
0.023 , respectively. An enhancement of the optical thermal responsibility of 43.5 times was obtained.

The thermal decay curves are shown in Fig. 10(b) and were fitted by

$$
\Delta I=\exp \left(t_{0}-t\right) / \tau
$$

where $\tau$ is the thermal decay time, which is defined by the time difference that the radiation intensity decreases from the normalized maximum (1) to 1/e. The thermal decay time $\tau$ of composite film and bare PI film are $13.02 \mathrm{~ms}$ and 10.44 $\mathrm{ms}$, respectively. Only a $2.58 \mathrm{~ms}$ decay time increase was induced by the Cr black absorber. Such a small thermal response time increase is attributed to the high thermal conductivity and low heat mass of the Cr black absorber.

Based on the working mechanization, if the Cr black absorbers with shorter wet-etching times are used, the optical thermal responsibility will decrease and the thermal decay time will increase. That is induced by the lower light absorption and higher mass density.

In conclusion, by using the Cr black absorber the high optical thermal conversion efficiency can be obtained without sacrificing the time response.

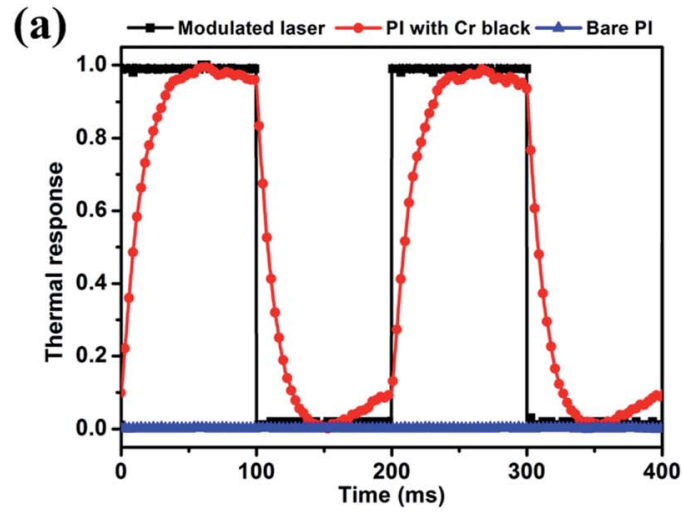

(b)

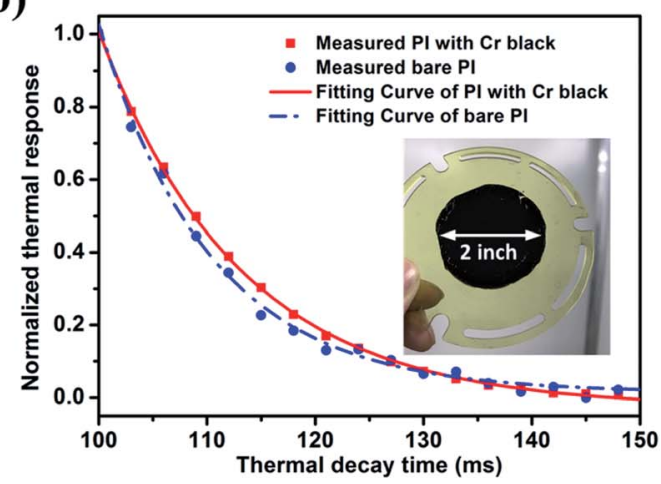

Fig. 10 (a) Optical thermal response of $\mathrm{Cr}$ black/PI composite film and bare PI film under a $5 \mathrm{~Hz}$ intensity modulated $532 \mathrm{~nm}$ laser excitation. (b) Thermal decay of composite film and bare PI film. The inset in (b) is a 2 inch free-standing $\mathrm{Cr}$ black/PI composite film. 


\section{Conclusions}

In summary, a simple and low-cost method to produce broadband porous Cr black absorber was proposed. By metal Cr film deposition and subsequent chemical wet-etching, an absorber with the thickness of no more than $400 \mathrm{~nm}$ was fabricated. The average absorption was higher than $93 \%$ in the range of $320-$ $800 \mathrm{~nm}$ and the absorption peak located at $530 \mathrm{~nm}$. Even extending to the NIR range (800-1800 nm), the absorption was still over $65 \%$. The broadband absorption property could be explained by porous nanostructures inside the $\mathrm{Cr}$ black absorber, where light internal multiple reflection happened. The absorption coefficient of the black $\mathrm{Cr}$ absorber was as high as $6.6 \mu \mathrm{m}^{-1}$. Compared to the $\mu \mathrm{m}$-thick perfect absorbers, porous thin layer $\mathrm{Cr}$ absorber is more suitable for the applications demanding flexibility and quick thermal response. The black $\mathrm{Cr}$ absorber was fabricated on a $500 \mathrm{~nm}$ free-standing flexible PI thin film with 2 inch diameter. The optical thermal properties of the composite film were investigated. At the same incident laser intensity, the thermal radiation intensity of the composite film was 43.5 times higher than that of bare PI film, while the thermal decay time only increased by $24.7 \%$ (from $10.44 \mathrm{~ms}$ to $13.02 \mathrm{~ms}$ ) with nearly doubled thickness. The novel properties and simple, cost-effective fabrication process make the $\mathrm{Cr}$ black/PI composite thin film very attractive to be used in optical thermal devices.

\section{Conflicts of interest}

The authors declare no conflict of interest.

\section{Acknowledgements}

This work was supported by the National Natural Science Foundation of China (Grant No. 61875011, 61835001, 61741502 and 61704166). Authors are thankful to the Analysis \& Testing Center, Micro-fabrication Center and National Key Laboratory of Color Science and Engineering in Beijing Institute of Technology for providing the characterization facility for this study.

\section{References}

1 T. Xiao, X. Fan, D. Fan and Q. Li, Polym. Bull., 2017, 74, 1-15. 2 M. Haruki, J. Tada, K. Tanaka, H. Onishi and Y. Tada, Thermochim. Acta, 2018, 662, 1-7.

3 T. Stieglitz, H. R. Beutel, M. Schuettler and J. U. Meyer, Biomed. Microdevices, 2000, 2, 283-294.

4 Y. Jiang, S. Yu, J. Li, L. Jia and C. Wang, Carbon, 2013, 63, 367-375.

5 Q. Yuan, P. Liu and G. L. Baker, J. Mater. Chem. A, 2015, 3, 3847-3853.

6 Y. J. Kim, S. J. Yu and Y. G. Jeong, RSC Adv., 2016, 6, 3010630114.

7 C. Xia, H. Tao, H. Jiang, B. Wei, G. Chen, X. Fang, M. Jin, R. A. Hayes, G. Zhou and L. Shui, Displays, 2015, 37, 79-85.

8 W. K. Jin, C. R. Sang, Q. H. Vu, J. Y. So, S. M. Lee, N. T. Mai and L. S. Park, Mol. Cryst. Liq. Cryst., 2009, 513, 214-226.
9 H. S. Jang, K. J. Sang and S. H. Nahm, Carbon, 2011, 49, 111116.

10 T. J. Kang, T. Kim, S. M. Seo, Y. J. Park and H. K. Yong, Carbon, 2011, 49, 1087-1093.

11 I. E. Araci, V. Demir, A. Kropachev, T. Skotheim, R. A. Norwood and N. Peyghambarian, Appl. Phys. Lett., 2010, 97, 041102.

12 K. Satori, K. Fukuchi, Y. Kurosawa, A. Hongo and N. Takeda, Proc. SPIE, 2001, 4328, 285-294.

13 Y. Yang, S. Nuo, L. Zhou, C. Xu, H. Wang, L. Zhang, Y. Li and Z. Li, Proc. SPIE, 2015, 9677, 967708.

14 C. M. Watts, X. Liu and W. J. Padilla, Adv. Mater., 2012, 24, OP98-OP120.

15 M. K. Hedayati, M. Javaherirahim, B. Mozooni, R. Abdelaziz, A. Tavassolizadeh, V. S. Chakravadhanula, V. Zaporojtchenko, T. Strunkus, F. Faupel and M. Elbahri, Adv. Mater., 2011, 23, 5409.

16 J. Z. Hao, Y. Seokho, T. Fatima, D. H. Werner and T. S. Mayer, ACS Nano, 2011, 5, 4641-4647.

17 J. A. Bossard, L. Lan, Y. Seokho, L. Liu, D. H. Werner and T. S. Mayer, ACS Nano, 2014, 8, 1517-1524.

18 H. Cheng, S. Chen, H. Yang, J. Li, X. An, C. Gu and J. Tian, J. Opt., 2012, 14, 85102-85106(85105).

19 Z. Liu, X. Liu, S. Huang, P. Pan, J. Chen, G. Liu and G. Gu, ACS Appl. Mater. Interfaces, 2015, 7, 4962-4968.

20 Z. Nan, Z. Peiheng, C. Dengmu, W. Xiaolong, X. Jianliang and D. Longjiang, Opt. Lett., 2013, 38, 1125-1127.

21 C. W. Chiu, C. W. Cheng, K. T. Lai, M. H. Shih, M. N. Abbas and Y. C. Chang, Opt. Express, 2012, 20, 10376-10381.

22 Z. Bingxin, Z. Yanhui, H. Qingzhen, K. Brian, K. Iam-Choon, C. Shufen and H. Tony Jun, Opt. Express, 2011, 19, 1522115228.

23 F. Xing, B. Zhao and W. Shi, Electrochim. Acta, 2013, 100, 157-163.

24 Y. F. Wang, W. G. Fu, M. Feng and X. W. Cao, Appl. Phys. A: Mater. Sci. Process., 2008, 90, 549-553.

25 H. Ye, X. J. Wang, W. Lin, C. P. Wong and Z. M. Zhang, Appl. Phys. Lett., 2012, 101, 141909.

26 H. Shi, J. G. Ok, H. W. Bacc and L. J. Guo, Appl. Phys. Lett., 2011, 99, 207402.

27 F. Ren, H. Yu, W. Li, M. Saleem, Z. Tian and P. Ren, RSC Adv., 2014, 4, 14419-14431.

28 B. Zheng, W. Wang, G. Jiang and X. Mei, Appl. Phys. B: Lasers Opt., 2016, 122, 180.

29 J. Gao, M. Raad, B. P. Bowen, R. N. Zuckermann and T. R. Northen, Anal. Chem., 2016, 88, 1625.

30 J. Yang, F. Luo, T. S. Kao, X. Li, G. W. Ho, J. Teng, X. Luo and M. Hong, Light: Sci. Appl., 2014, 3, e185.

31 J. Wang, Y. Liang, P. Huo, D. Wang, J. Tan and T. Xu, Appl. Phys. Lett., 2017, 111, 251102.

32 F. Peixun, B. Benfeng, L. Jiangyou, J. Dafa, J. Guofan, Z. Hongjun and Z. Minlin, Nano Lett., 2015, 15, 5988-5994.

33 T. Ji, L. Peng, Y. Zhu, F. Yang, Y. Cui, X. Wu, L. Liu, S. He, F. Zhu and Y. Hao, Appl. Phys. Lett., 2015, 106, 495-520.

34 D. Panjwani, A. Dutta, J. Nath, H. Heinrich and R. E. Peale, J. Appl. Phys., 2015, 118, 154307. 
35 X. Hu, S. Qin, J. Tian and M. Hu, Sol. Energy Mater. Sol. Cells, 1988, 17, 207-215.

36 D. Panjwani, M. Yesiltas, S. Singh, E. D. Barco, R. E. Peale, C. Hirschmugl and J. Sedlemair, Infrared Phys. Technol., 2014, 66, 1-5.

37 N. Jiang and J. Silcox, J. Appl. Phys., 2000, 87, 3768-3776.

38 J. M. Burkstrand, J. Appl. Phys., 1981, 52, 4795-4800.

39 P. B. Johnson and R. W. Christy, Phys. Rev. B: Solid State, 1974, 9, 5056-5070.
40 M. Steglich, D. Lehr, S. Ratzsch, T. Käsebier, F. Schrempel, E. B. Kley and A. Tünnermann, Laser Photonics Rev., 2014, 8, L13-L17.

41 Z. Liu, H. Liu, X. Wang, H. Yang and J. Gao, Sci. Rep., 2017, 7, 42750.

42 A. Greppmair, B. Stoib, N. Saxena, C. Gerstberger, P. MüllerBuschbaum, M. Stutzmann and M. S. Brandt, Rev. Sci. Instrum., 2017, 88, 044903. 